\title{
Penerapan Algoritma K-Means Clustering dalam Mengelompokkan Jumlah Posyandu Aktif Berdasarkan Provinsi
}

\author{
Riski Sundari', Solikhun², Eka Irawan ${ }^{3}$, Edy Satria ${ }^{4}$ \\ ${ }^{1,4}$ Mahasiswa STIKOM Tunas Bangsa , ${ }^{2}$ AMIK Tunas Bangsa, ${ }^{3}$ STIKOM Tunas Bangsa \\ Jln. Jend Sudirman Blok A No.1-3 Pematangsiantar, Kode Pos: 21127 Sumatera Utara-Indonesia \\ Email : Sundaririski130@gmail.com
}

\begin{abstract}
Posyandu (Integrated Service Post) is one form of Community-based Health Efforts (UKBM) carried out with the community, to empower and provide facilities to the community to obtain health services for mothers, infants and toddlers. The Posyandu program is an effort to reduce the impact of the economic crisis on reducing the nutritional status of maternal and child health. This study discusses the grouping of the number of active posyandu based on provinces in Indonesia. The method used in the research is Data mining with the K-Means Clustering algorithm. By using this method the data obtained can be grouped into several clusters. This study uses secondary data, namely data obtained from intermediary media recorded on the website of the Indonesian Ministry of Health with the url address https://www.depkes.go.id/. The results obtained in this study are grouping the number of active posyandu grouped into 2 clusters, the highest cluster and the lowest cluster. There are 3 provinces included in the highest cluster and there are 31 provinces included in the lowest cluster. From the results of this study, it will be found that the provinces that get the lowest cluster in the number of active posyandu in Indonesia, It is hoped that this research can provide input to the relevant government, to pay more attention to the provinces in Indonesia which have the lowest cluster to activate the posyandu program in the province. Because posyandu is very important for children's health. If the child has never done a posyandu then he or she will not receive nutritional intake according to the child's needs.
\end{abstract}

Keywords: Data Mining, Clustering, K-Means, Posyandu

Abstrak - Posyandu (Pos Pelayanan Terpadu) merupakan salah satu bentuk Upaya Kesehatan Bersumberdaya Masyarakat (UKBM) yang dilaksanakan bersama masyarakat, untuk memberdayakan dan memberikan kemudahan kepada masyarakat guna memperoleh pelayanan kesehatan bagi ibu, bayi dan anak balita. Program Posyandu merupakan upaya untuk mengurangi dampak dari krisis ekonomi terhadap penurunan status gizi kesehatan ibu dan anak. Penelitian ini membahas tentang pengelompokkan jumlah posyandu aktif berdasarkan provinsi di Indonesia. Metode yang digunakan dalam penelitian adalah Data mining dengan algoritma K-Means Clustering. Dengan menggunakan metode ini data-data yang diperoleh dapat dikelompokkan menjadi 2 cluster. Penelitian ini menggunakan data sekunder yaitu data diperoleh dari media perantara yang terekam di situs Departemen Kesehatan Indonesia dengan alamat url https://www.depkes.go.id/. Hasil yang didapat dalam penelitian ini adalah pengelompokkan jumlah posyandu aktif yang di kelompokkan menjadi 2 cluster yaitu cluster tertinggi dan cluster terendah. Terdapat 3 provinsi yang termasuk kedalam cluster tertinggi dan terdapat 31 provinsi yang termasuk kedalam cluster terendah. Dari hasil penelitian ini provinsi yang mendapat cluster terendah pada jumlah posyandu aktif, Diharapkan dapat memberikan masukan kepada pihak pemerintah terkait, Agar lebih memperhatikan provinsi yang mendapatkan cluster terendah untuk membenahi program posyandu di provinsi tersebut. Karena posyandu sangat penting untuk kesehatan 
anak. Jika anak tidak pernah melakukan posyandu maka tidak akan menerima asupan gizi yang sesuai dengan kebutuhan anak.

Kata kunci: Data Mining, Clustering, K-Means, Posyandu

\section{PENDAHULUAN}

Data Mining merupakan istilah yang dipakai untuk menjabarkan suatu penemuan ilmu pengetahuan pada database. Di dalam teknik data mining terdapat tahapan yang diaplikasikan ke teknik statistik, matematika, kecerdasan buatan dan machine learning untuk mengekstrak dan mengidentifikasi suatu informasi bermanfaat serta pengembangan ilmu pengetahuan yang berkaitan dengan beberapa basis data yang besar. Data Mining termasuk metode yang sering dibutuhkan dalam pengolahan data berskala besar, maka data mining mempunyai akses penting pada bidang kehidupan diantaranya yaitu bidang industri, bidang keuangan, cuaca, ilmu dan teknologi. Pada teknik data mining terdapat metodemetode yang dapat digunakan yaitu klarifikasi, clustering, regresi, seleksi variabel, dan market basket analisis [1]. Salah satu metode di data mining yaitu K-Means. $K$ Means adalah metode bersifat non hierarki yang bekerja untuk menyimpan data yang sudah ada menjadi satu bentuk cluster atau bisa menjadi lebih dari satu cluster kelompok sehingga data yang mempunyai karakteristik yang sama dikelompokkan menjadi satu cluster yang sama dan data yang mempunyai karakteristik yang berbeda dikelompokkan ke dalam kelompok yang lainnya [2]. Metode K-Means adalah metode yang termasuk dalam algoritma clustering berbasis jarak yang membagi data ke dalam sejumlah cluster dan algoritma ini hanya bekerja pada atribut numerik [3]. Berdasarkan penelitian yang telah dilakukan dalam pemanfaatan metode data mining khususnya clustering dalam melakukan pengelompokkan data yang ditulis dalam jurnal karya ilmiah. Salah satunya yang dilakukan oleh Merry Lanoh, 2015 yang berjudul "Hubungan Pemanfaatan Posyandu Dengan Status Gizi Balita Di Wilayah Kerja Puskesmas Ranotana Weru Kota Manado" . Penelitian ini menggunakan desain Cross Sectional yang bersifat analitik untuk mengetahui hubungan antara pemanfaatan posyandu dengan status gizi balita dengan menggunakan data primer. Untuk mengetahui hubungan pemanfaatan posyandu dengan status gizi balita, maka dilakukan analisis dengan menggunakan uji statistik ChiSquare pada tingkat kemaknaan $\alpha=0,05$ atau $p$ value $<0,05$ dengan hasil data yang menunjukan balita yang tidak memanfaatkan posyandu dengan status gizi baik berjumlah 10 orang $(43,5 \%)[4]$. Penelitian diatas dijadikan acuan oleh penulis dalam menyelesaikan penelitian sehingga penulis dapat menambah ilmu teori dalam mengkaji suatu karya ilmiah yang sedang dilakukan. Berdasarkan penelitian sebelumnya, penulis tidak menemukan judul / teori yang sama dengan judul penelitian penulis. Namun, penulis menjadikan beberapa penelitian sebagai referensi bahan kajian pada penelitian penulis.

Kesehatan merupakan hak asasi setiap manusia, salah satu upaya untuk mewujudkan tujuan bangsa Indonesia menciptakan generasi-generasi yang cerdas yaitu dengan memberikan pelayanan kesehatan yang tujuan sasarannya untuk 
masyarakat adalah program posyandu. Posyandu adalah singkatan dari pos pelayanan terpadu yang didirikan oleh pemerintah untuk mengontrol kesehatan masyarakat dengan dibantu pihak petugas kesehatan Posyandu termasuk Upaya Kesehatan Bersumberdaya Masyarakat (UKBM), konsep posyandu sangat berkaitan dengan keterpaduan. Tetapi banyak di bagian provinsi Indonesia yang masih tidak menerapkan kegiatan Posyandu. Oleh karena itu, perlu adanya sistem yang memungkinkan untuk menentukan provinsi yang tidak aktif pada kegiatan posyandu tersebut. Berdasarkan latar belakang diatas, maka penulis mengangkat judul "Penerapan Algoritma K-Means Clustering Dalam Mengelompokkan Jumlah Posyandu Aktif Berdasarkan Provinsi“. Hasil dari penelitian diharapkan dapat dijadikan kontribusi untuk Pemerintah Indonesia dalam hal membenahi atau meningkatkan fasilitas pada posyandu di provinsi Indonesia yang mendapatkan cluster terendah agar ibu hamil dan balita mendapatkan pelayanan sesuai dengan kebutuhan mereka tanpa adanya kekurangan.

\section{METODOLOGI PENELITIAN}

\subsection{METODE PENELITIAN}

Metode penelitian merupakan suatu tahapan yang digunakan sehubungan dengan penelitian yang dilakukan. Dengan memahami suatu metode penelitian, bukan hanya dapat menyelesaikan permasalahan dalam penelitian, tetapi dapat menambah wawasan dalam bidang keilmuan yang sedang di geluti. Memahami metode juga dapat memperbanyak teori-teori baru yang sangat bermanfaat bagi masyarakat luas dan dunia pendidikan. Penelitian dilakukan untuk mengaplikasikan data mining dalam mengelompokkan jumlah posyandu aktif berdasarkan provinsi di Indonesia. Adapun keilmuan dari data mining yang dibutuhkan pada penelitian ini adalah algoritma clustering. Pengelompokkan dilakukan untuk mencari provinsi mana saja yang mendapatkan cluster terendah, yang nantinya akan memberikan masukan kepada pihak pemerintah yang terkait agar lebih memperhatikan provinsi tersebut dan meningkatkan kualitas pelayanan posyandu pada provinsi yang mendapatkan cluster terendah.

1. Metode Pengumpulan Data

Penggunaan metode yang dibutuhkan oleh penulis dalam pengumpulan data penelitian sebagai berikut:

a) Penulis mengambil data melalui media perantara seperti situs web Departemen Kesehatan Indonesia dengan alamat url https://www.depkes.go.id/_untuk memperoleh data asli posyandu aktif pada tahun 2017 yang terdiri dari 34 provinsi di Indonesia.

b) Literatur, penulis membaca buku yang berkaitan dengan teori penelitian yang penulis lakukan, untuk mempermudah dalam menyelesaikan proses penelitian yang penulis lakukan.

\subsection{ANALISA PERMASALAHAN}

Berdasarkan hasil analisa yang dilakukan penulis dapat disimpulkan bahwa permasalahan yang menjadi dasar dilakukannya penelitian ini adalah belum maksimalnya kegiatan posyandu terkhususnya pada provinsi yang ada di 
Indonesia. Masih banyaknya kegiatan posyandu yang belum diterapkan ataupun dilaksanakan pada provinsi di Indonesia.

\subsection{METODE K-MEANS}

Algoritma K-Means merupakan metode untuk menggelompokkan suatu data yang dilakukan berdasarkan titik pusat cluster secara iteratif dimana letak cluster masing-masing data ditemukan jarak terendah setiap data pada pusat cluster. Dalam algoritma K-Means proses iterasi dinyatakan berhenti jika nilai pusat cluster hasil iterasi dengan nilai pusat cluster hasil iterasi sebelumnya bernilai sama atau letak cluster data tidak mengalami perubahan lagi.

\subsection{PERANCANGAN PENELITIAN}

Pada bagian perancangan penelitian berisi diagram alir yang terdiri dari proses posyandu aktif yang terlihat pada gambar 1 berikut :

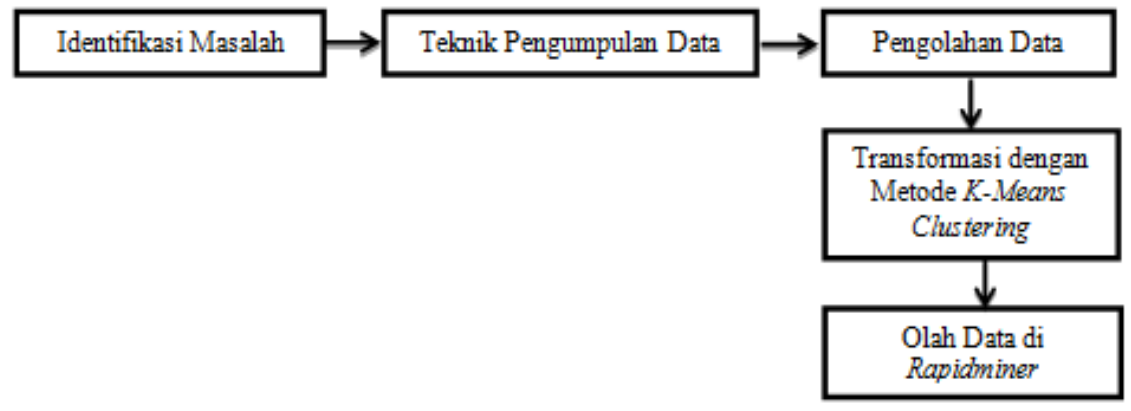

Gambar 1. Diagram Alir Proses Posyandu Aktif

\subsection{FLOWCHART ALGORITMA K-MEANS CLUSTERING}

Dalam perhitungan K-Means Clustering hal yang utama dilakukan adalah menentukan jumlah cluster yang akan digunakan dalam penelitian, setelah mendapatkan jumlah cluster langkah selanjutnya yaitu menetapkan jumlah cluster yang artinya memilih nilai pada data yang akan diolah menggunakan rumus clustering. Kemudian data diolah, maka tahap berikutnya adalah data diproses untuk membentuk pengelompokan data ke dalam program posyandu aktif sesuai variabel yang sudah ditentukan. Jika sudah mendapatkan hasil dari perhitungan, maka berikutnya memasukkan data kedalam aplikasi rapidminer untuk mendapatkan hasil dari perhitungan menggunakan software. 


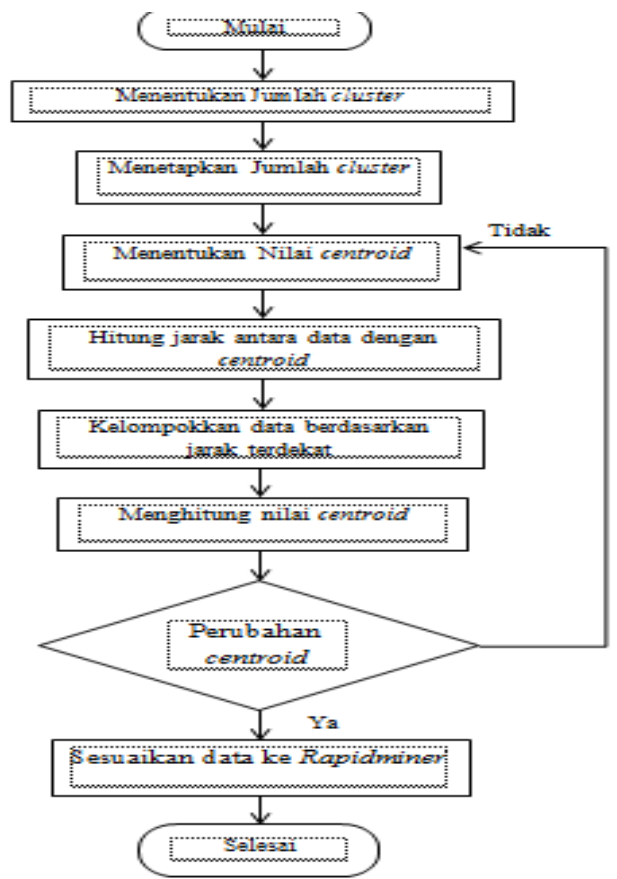

Gambar 2. Flowchart Proses K-Means Clustering

\subsection{Perhitungan Manual Metode K-Means}

Pada tahapan ini dilakukan analisis data posyandu aktif menurut provinsi di Indonesia dengan tool Rapidminer. Rapidminer adalah sebuah software pilihan yang betugas untuk mengekstraksi data dengan metode data mining. Berikut adalah data posyandu aktif yang diambil oleh penulis :

1. Menentukan Data yang akan diolah

Berikut adalah data posyandu aktif yang diambil penulis melalui situs web Departemen Kesehatan :

Tabel 1. Data Posyandu Aktif Menurut Provinsi Tahun 2017

(Sumber : Data Departemen Kesehatan Indonesia, 2017)

\begin{tabular}{|c|l|r|r|r|}
\hline No. & \multicolumn{1}{|c|}{ Provinsi } & Total Posyandu & \multicolumn{1}{c|}{ Posyandu } & \multicolumn{1}{c|}{ Presentasi Posyandu } \\
\hline 1 & Aceh & 6.484 & 1.428 & 22,02 \\
\hline 2 & Sumatera Utara & 15.307 & 7.783 & 50,85 \\
\hline 3 & Sumatera Barat & 13.122 & 5.403 & 41,18 \\
\hline 4 & Riau & 5.343 & 2.654 & 49,67 \\
\hline 5 & Jambi & 4.836 & 1.198 & 24,77 \\
\hline 6 & Sumatera Selatan & 6.557 & 5.578 & 85,07 \\
\hline 7 & Bengkulu & 2.026 & 631 & 31,15 \\
\hline 8 & Lampung & 7.858 & 5.355 & 68,15 \\
\hline 9 & Kep. Bangka Belitung & 1.161 & 811 & 69,85 \\
\hline 10 & Kepulauan Riau & 1.364 & 700 & 51,32 \\
\hline 11 & DKI Jakarta & 5.969 & 1.59 & 26,64 \\
\hline 12 & Jawa Barat & 50.894 & 29.388 & 57,74 \\
\hline 13 & Jawa Tengah & 48.891 & 32.397 & 66,26 \\
\hline 14 & DI Yogyakarta & 3.868 & 2.991 & 77,33 \\
\hline 15 & Jawa Timur & 46.598 & 34.245 & 73,49 \\
\hline 16 & Banten & 10.281 & 3.268 & 31,79 \\
\hline
\end{tabular}




\begin{tabular}{|r|l|r|r|r|}
\hline No. & \multicolumn{1}{|c|}{ Provinsi } & Total Posyandu & Posyandu & Presentasi Posyandu \\
\hline 17 & Bali & 4.482 & 2.875 & 64,15 \\
\hline 18 & Nusa Tenggara Barat & 7.088 & 3.623 & 51,11 \\
\hline 19 & Nusa Tenggara Timur & 9.976 & 5.532 & 55,45 \\
\hline 20 & Kalimantan Barat & 4.803 & 1.067 & 22,22 \\
\hline 21 & Kalimantan Tengah & 2.164 & 383 & 17,70 \\
\hline 22 & Kalimantan Selatan & 3.06 & 695 & 22,71 \\
\hline 23 & Kalimantan Timur & 4.921 & 2.38 & 48,36 \\
\hline 24 & Kalimantan Utara & 476 & 221 & 46,43 \\
\hline 25 & Sulawesi Utara & 0 & 0 & 0 \\
\hline 26 & Sulawesi Tengah & 3.334 & 1.166 & 34,97 \\
\hline 27 & Sulawesi Selatan & 9.704 & 5.4 & 55,65 \\
\hline 28 & Sulawesi Tenggara & 3.2 & 1.42 & 44,38 \\
\hline 29 & Gorontalo & 0 & 0 & 0 \\
\hline 30 & Sulawesi Barat & 1.851 & 1.06 & 57,27 \\
\hline 31 & Maluku & 1.121 & 370 & 33,01 \\
\hline 32 & Maluku Utara & 0 & 0 & 0 \\
\hline 33 & Papua Barat & 3.525 & 2.241 & 85,71 \\
\hline 34 & Papua & & & 63,57 \\
\hline
\end{tabular}

2. Menentukan Jumlah cluster

Data yang sudah dipilih selanjutnya akan diproses dengan memasukkan data ke dalam rumus clustering dengan menerapkan algoritma $k$-means kedalam aplikasi rapidminer untuk mengcluster data menjadi dua cluster. Data yang sudah dipilih akan dimasukkan kedalam tool rapidminer. Sehingga dapat di cluster menjadi dua cluster yakni posyandu aktif rendah, posyandu aktif tinggi.

3. Menentukan Centroid

Untuk mendapatkan nilai titik tengah pada centroid dari data, maka perlu membuat suatu ketentuan bahwa clusterisasi yang diinginkan adalah 2, Penentuan cluster dibagi menjadi 2 bagian yaitu cluster tingkat tinggi (C1), cluster tingkat rendah (C2). Untuk nilai titik cluster ditentukan dengan cara mengambil nilai terbesar (maksimum) untuk cluster tingkat tinggi (C1), dan nilai terkecil (minimum) untuk cluster tingkat rendah (C2). Nilai titik cluster dapat dilihat pada tabel berikut :

Tabel 2. Centroid Awal

\begin{tabular}{|c|c|c|c|c|}
\hline \multirow{2}{*}{ Centroid } & $\mathrm{C} 1$ & 50984 & 34245 & 77,33 \\
\cline { 2 - 5 } & $\mathrm{C} 2$ & 0 & 0 & 0 \\
\hline
\end{tabular}

\section{Menghitung Jarak dari Centroid}

Untuk menghitung jarak antara titik Centroid dengan titik tiap objek menggunakan Euclidian Distance. Rumus untuk menghitung jarak dari Centroid adalah :

$$
D e=\sqrt{(x i-s i)^{2}+(y i-t i)^{2}}
$$

Maka perhitungan untuk jarak dari Centroid ke-1 sebagai berikut : 


$$
\begin{aligned}
\mathrm{D}_{\mathrm{A} 1, \mathrm{c} 1} & =\sqrt{(6.484-50984)^{2}+(1.428-34245)^{2}+(22,02-77,33)^{2}} \\
& =55.292
\end{aligned}
$$

Dan seterusnya sampai dengan $\mathrm{D}_{\mathrm{A} 34, \mathrm{c1}}$. Selanjutnya perhitungan untuk jarak dari Centroid ke-2 adalah sebagai berikut:

$$
\begin{aligned}
\mathrm{D}_{\mathrm{A} 1, \mathrm{c} 2} & =\sqrt{(6.484-0)^{2}+\left(1.428-0^{2}+(22,02-0)^{2}\right.} \\
& =6.639
\end{aligned}
$$

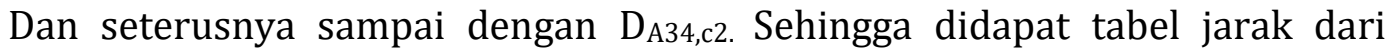

\begin{tabular}{|c|c|c|c|c|c|}
\hline Provinsi & $\mathrm{C} 1$ & $\mathrm{C} 2$ & $\begin{array}{c}\text { Jarak } \\
\text { Terpendek }\end{array}$ & $\mathrm{C} 1$ & $\mathrm{C} 2$ \\
\hline Aceh & 55292 & 6639 & 6639 & & 1 \\
\hline Sumatera Utara & 44419 & 17172 & 17172 & & 1 \\
\hline Sumatera Barat & 47596 & 14191 & 14191 & & 1 \\
\hline Riau & 55508 & 5966 & 5966 & & 1 \\
\hline Jambi & 56760 & 4982 & 4982 & & 1 \\
\hline Sumatera Selatan & 52873 & 8609 & 8609 & & 1 \\
\hline Bengkulu & 59387 & 2122 & 2122 & & 1 \\
\hline Lampung & 51908 & 9509 & 9509 & & 1 \\
\hline K. Bangka Belitung & 60001 & 1418 & 1418 & & 1 \\
\hline Kepulauan Riau & 59895 & 1534 & 1534 & & 1 \\
\hline DKI Jakarta & 55612 & 6177 & 6177 & & 1 \\
\hline Jawa Barat & 4858 & 58770 & 4858 & 1 & \\
\hline Jawa Tengah & 2792 & 58651 & 2792 & 1 & \\
\hline DI Yogyakarta & 56540 & 4890 & 4890 & & 1 \\
\hline Jawa Timur & 4386 & 57828 & 4386 & 1 & \\
\hline Banten & 51150 & 10788 & 10788 & & 1 \\
\hline Bali & 56094 & 5325 & 5325 & & 1 \\
\hline NTB & 53522 & 7960 & 7960 & & 1 \\
\hline NTT & 50061 & 11407 & 11407 & & 1 \\
\hline Kalimantan Barat & 56864 & 4920 & 4920 & & 1 \\
\hline Kalimantan Tengah & 59414 & 2198 & 2198 & & 1 \\
\hline Kalimantan Selatan & 58501 & 3138 & 3138 & & 1 \\
\hline Kalimantan Timur & 56011 & 5467 & 5467 & & 1 \\
\hline Kalimantan Utara & 60899 & 527 & 527 & & 1 \\
\hline Sulawesi Utara & 61417 & 0 & 0 & & 1 \\
\hline Sulawesi Tengah & 58006 & 3532 & 3532 & & 1 \\
\hline Sulawesi Selatan & 50359 & 11105 & 11105 & & 1 \\
\hline Sulawesi Tenggara & 57972 & 3501 & 3501 & & 1 \\
\hline Gorontalo & 61417 & 0 & 0 & & 1 \\
\hline Sulawesi Barat & 59290 & 2134 & 2134 & & 1 \\
\hline Maluku & 60281 & 1181 & 1181 & & 1 \\
\hline Maluku Utara & 61417 & 0 & 0 & & 1 \\
\hline Papua Barat & 59870 & 1560 & 1560 & & 1 \\
\hline Papua & 57242 & 4178 & 4178 & & 1 \\
\hline
\end{tabular}
Centroid dan mencari nilai yang sama dari kedua centroid. Tabel jarak dari centroid sebagai berikut :

Tabel 3. Data Perhitungan Algoritma K-Means Hasil Iterasi Ke-1 


\section{Menentukan Cluster atau Pengelompokkan}

Dalam menentukan Cluster dengan nilai Cluster berdasarkan nilai yang sama dari nilai Cluster dan diletakkan pada Cluster yang sesuai dengan nilai sama pada Iterasi Selanjutnya dalam metode K-Means, perhitungan berhenti apabila Cluster pada iterasi yang dihasilkan sama pada iterasi sebelumnya. Maka selanjutnya mencari Cluster untuk iterasi berikutnya hingga nilai iterasinya sama. Untuk mencari nilai Centroid selanjutnya dengan menggunakan Centroid baru pada Iterasi ke-1 dengan menjumlahkan nilai sesuai yang tertera pada Cluster di tabel diatas. Adapun Centroid baru untuk mencari Cluster selanjutnya adalah dengan menjumlahkan nilai yang terpilih pada Cluster tersebut kemudian membagikannya sebanyak jumlah nilai sebagai berikut :

$C_{1}=(50.894+48.891+46.598) / 3=48.794$

Lakukan perhitungan untuk Cluster berikutnya dengan cara yang sama seperti pencarian pada iterasi ke-1. Dalam penelitian ini Cluster berhenti hingga iterasi ke2 , karena pada iterasi ke-2 data yang diperoleh sama dengan iterasi ke-1. Maka perhitungan hanya sampai iterasi ke-2.

Dari tabel Cluster Iterasi ke-1 dan tabel Cluster Iterasi ke-2 memiliki nilai Cluster yang sama atau tidak berubah pada cluster terakhir maka perhitungan dihentikan dan hasil yang diperoleh yaitu :

a) Cluster 1 (C1) mendapatkan 3 data provinsi dalam artian bahwa kelompok pertama termasuk kategori Posyandu Aktif Tinggi Pada Tahun 2017.

b) Cluster 2 (C2) mendapatkan 31 data provinsi dalam artian bahwa kelompok kedua termasuk kategori Posyandu Aktif Rendah pada tahun 2017.

\section{HASIL DAN PEMBAHASAN}

\subsection{HASIL}

Pada bagian ini penulis menguraikan hasil yang di dapat dalam proses penelitian yang telah dilakukan sebelumnya. Penulis menggunakan data posyandu aktif berdasarkan provinsi di Indonesia. Dalam mendukung proses penelitian, penulis memakai software Rapidminer 5.3 untuk validasi hasil perhitungan manual dengan menggunakan aplikasi dalam mengelompokkan jumlah posyandu aktif. Data yang telah diperoleh akan ditransformasikan ke dalam format data excel 2010 kemudian diolah dengan algortima $k$-means untuk menemukan cluster posyandu aktif tinggi, posyandu aktif rendah dan mengetahui provinsi mana yang termasuk dalam jumlah posyandu aktif rendah. Berikut adalah hasil impelementasi yang didapat dari aplikasi rapidminer : 


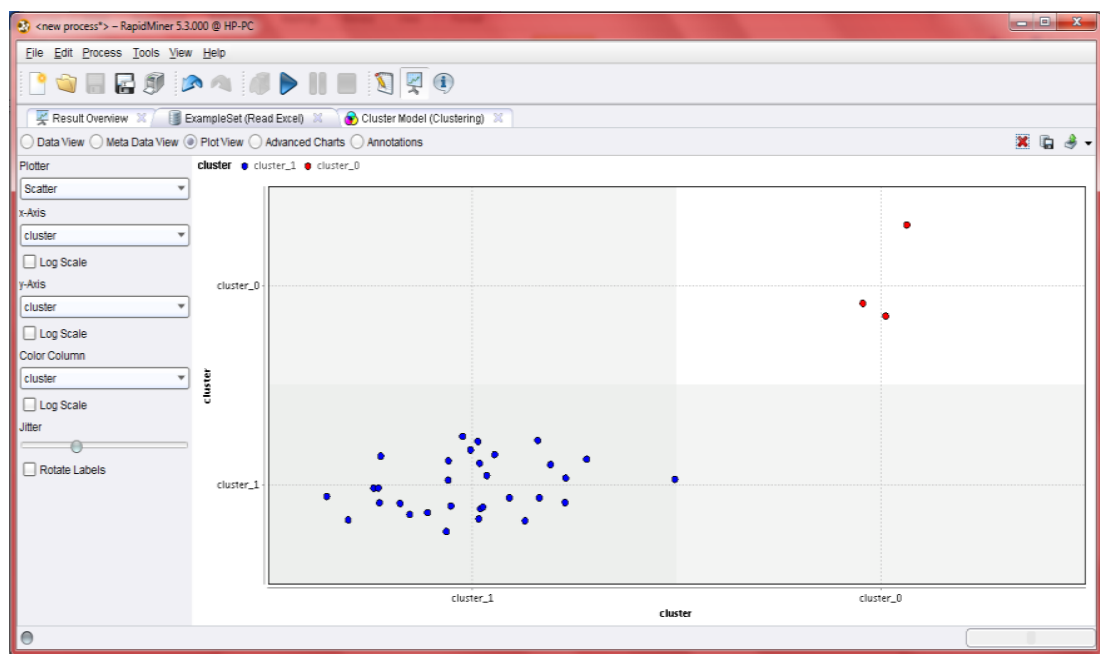

Gambar 3. Grafik Clustering

Berdasarkan pada gambar 3. dapat diketahui bahwa titik berwarna merah adalah cluster 0 , titik berwarna biru adalah cluster 1 . Hasil yang diperoleh dari pengklasteran diatas adalah cluster 0 (tertinggi) berjumlah 3 provinsi yaitu Jawa Barat, Jawa Tengah, dan Jawa Timur dan cluster 1 (terendah) berjumlah 31 provinsi seperti yang terlihat pada gambar dibawah

\subsection{PEMBAHASAN}

Berdasarkan implementasi perhitungan cluster menggunakan software rapidminer sebelumnya, hasil yang diperoleh adalah jumlah provinsi yang termasuk cluster tertinggi (cluster 0) yaitu provinsi Jawa Barat, Jawa Tengah, dan Jawa Timur. Sedangkan provinsi yang termasuk ke dalam cluster terendah (cluster 1) terdapat 31 provinsi yang tertera pada gambar 4.12. sama halnya dengan perhitungan manual k-means menggunakan Microsoft Excel, hasil yang diperoleh pada iterasi 1 dan iterasi 2 terdapat 3 provinsi yang termasuk di cluster 1 (cluster 0 pada rapidminer) sedangkan yang termasuk dalam cluster 2 (cluster 1 pada rapidminer) terdapat 31 provinsi yang hasilnya balance dengan implementasi di software rapidminer. Pada data asli dari Departemen Kesehatan Presentasi Posyandu Aktif di Indonesia sebanyak 56,57\%, sedangkan dari hasil perhitungan dengan menggunakan metode $K$-Means Clustering yang sudah dikelompokkan mendapatkan hasil 91\% (31/34) untuk cluster terendah dan 0,9\% (3/34) untuk cluster tertinggi.

\section{KESIMPULAN}

Berdasarkan hasil penelitian dan pembahasan tentang Penerapan Algoritma K-Means Clustering Dalam Mengelompokkan Jumlah Posyandu Aktif Berdasarkan Provinsi disimpulkan sebagai berikut :

a) Data Mining dengan Algoritma K-Means Clustering berhasil diterapkan pada data posyandu aktif dengan tujuan untuk mengelompokkan jumlah posyandu aktif yang ada di provinsi Indonesia.

b) Penelitian membahas tentang penerapan data mining untuk pengelompokkan jumlah posyandu aktif berdasarkan provinsi di Indonesia menggunakan 
algoritma $k$-means clustering diimplementasikan dengan bantuan aplikasi rapidminer 5.3 untuk membuktikan bahwa perhitungan manual hasilnya sama dengan perhitungan pada aplikasi.

c) Dari hasil perhitungan algoritma $k$-means clustering dengan nilai $\mathrm{k}=2$ dan centroid untuk cluster Tertinggi pada C1 adalah sebanyak 3 Provinsi yaitu (Jawa Barat, Jawa Tengah, Jawa Timur), dan hasil untuk cluster terendah pada C2 adalah sebanyak 31 Provinsi yaitu (Aceh, Sumatera Utara, Sumatera Barat, Riau, Jambi, Sumatera Selatan, Bengkulu, Lampung, Kep. Bangka Belitung, Kepualuan Riau, DKI Jakarta, DI Yogyakarta, Banten, Bali, NTB, NTT, Kalimantan Barat, Kalimantan Tengah, Kalimantan Timur, Kalimantan Utara, Sulawesi Utara, Sulawesi Tengah, Sulawesi Tenggara, Gorontalo, Sulawesi Barat, Maluku, Maluku Utara, Papua Barat, Papua).

\section{DAFTAR PUSTAKA}

[1] L. Maulida, "KUNJUNGAN WISATAWAN KE OBJEK WISATA UNGGULAN DI PROV. DKI JAKARTA DENGAN K-MEANS," vol. 2, no. 3, pp. 167-174, 2018.

[2] B. M. Metisen and H. L. Sari, "ANALISIS CLUSTERING MENGGUNAKAN METODE KMEANS DALAM PENGELOMPOKKAN PENJUALAN PRODUK PADA SWALAYAN FADHILA," vol. 11, no. 2, pp. 110-118, 2015.

[3] W. M. P. Dhuhita, "CLUSTERING MENGGUNAKAN METODE K-MEANS UNTUK," vol. 15, no. 2, 2015.

[4] M. Lanoh and M. Karundeng, "HUBUNGAN PEMANFAATAN POSYANDU DENGAN STATUS RANOTANA WERU KOTA MANADO,” vol. 3, 2015. 